\title{
Organizational design in the context of supply chain sustainability: A conceptual model
}

\author{
S. M. Ali ${ }^{\mathrm{a}}$, Md. I. Alam ${ }^{\mathrm{b}}$ and S. Bhowmick
}

${ }^{a}$ Assistant Professor, Department of Industrial and Production Engineering, Bangladesh University of Engineering and Technology, Dhaka-1000, Bangladesh

${ }^{b}$ Department of Industrial and Production Engineering, Bangladesh University of Engineering and Technology, Dhaka-1000, Bangladesh

\begin{tabular}{l}
\hline A R T I C L E I N F O \\
\hline Article history: \\
Received October 1, 2011 \\
Received in Revised form \\
November, 14, 2011 \\
Accepted 15 February 2012 \\
Available online \\
5 March 2012 \\
\hline Keywords: \\
Organizational structure \\
Supply chain effectiveness and \\
performance \\
Sustainable organization
\end{tabular}

\section{Introduction}

The ongoing shifts in the way businesses compete in an increasingly competitive and dynamic global environment call for reviewing the ingrained concepts of organizational design that are guided by the more traditional strategy-structure-conduct paradigm. Amongst myriad ways organizations pursue competitive advantage in their supply management efforts, the most common are outsourcing, supplier development or strategic alliances and partnerships. However, the more mundane topic of organizational design is rarely mentioned. Except for cross-functional teaming, organizational design has received limited attention from supply management researchers.

\footnotetext{
* Corresponding author.

E-mail addresses: syed.mithun@gmail.com (S. Ali)

(c) 2012 Growing Science Ltd. All rights reserved. doi: 10.5267/j.msl.2012.03.006
} 
Supply chain executives face ongoing pressure from their customers and the regulators to reduce carbon emission and run "greener" operations. While the impression persists in many organizations that implementing more sustainable processes and techniques will be costly. But high performance supply chain study suggests that this does not have to be the case. We have interviewed supply chain executives to identify the performance characteristics of supply chain organizations that are achieving high performance in both effectiveness and efficiency. We also asked several questions about their performance against key sustainability measures.

Organizational design is a broad concept referring to the process of assessing and selecting the structure and formal system of communication, division of labor, coordination, control, authority and responsibility required to achieve an organization's goals (Hamel \& Pralahad, 2001). One way to think about an organization's design is as a complex web reflecting the pattern of interactions and coordination of technology, tasks and human components (Silvestri, 1997). Although design is often thought of in terms of organizational structure, an organization's design is much more complex and detailed than the lines and boxes that appear on an organizational chart (Champoux, 2000). The design actually determines the structure of the organization in order to suit technology, people and task of the organization.

Supply chain of a company is comprised of all parties concerned, directly or indirectly, in completing customer requests. Numerous studies have been conducted in the field of supply chain management , the main studies in sustainability has been focused primarily on the financial impacts of specific environmental behaviors such as pollution control (Hart \& Ahuja, 1996),or reverse logistics (Mukhopadhyay \& Setaputra 2006). There are limited studies viewing what would be the pattern of an organization and how it should be structured on the overall well-being of the firm to optimize sustainable supply chain. Effective integration of supply chain with the organization is must for its success in this competitive environment. Supply chain integration refers to coordination mechanisms in the form of business processes that should be streamlined and interconnected both within and outside company boundaries (Romano, 2003). Theorists say supply chain design, planning and operation decisions play a significant role in the success or failure of a firm. Despite the awareness that integration is important, companies are failing in their attempts at internal and external integration mainly because of lack of understanding how sustainability issues are involved at different stages of product life cycle and most importantly due to the absence of an integrated model (Jayaram \& Tan 2010). Trent (2004) proposed how the organization design can be utilized in procurement and supply management. But, in different literatures, the effect of the organizational design in the whole supply chain system is absent.

This research aims to determine the effect of Organizational design and structure on the supply chain effectiveness and performance. In achieving this aim, four correlative objectives with respective research questions are outlined as follows:

1. To determine the factors /dimensions which are important to make the organization sustainable in the context of effective supply chain or (global supply chain) or sustainable supply chain. (What are the key factors that ensure a sustainable organization in the context of effective supply chain or global supply chain?)

2. To study the existing organizational structure and the active supply chain of the concerned organizations. (What is the design/structure of the organization? What type of supply chain does the organization maintain?)

3. To determine the correlation between Organizational design/structure and supply chain effectiveness and performance. (What is the relation between Organizational design/structure and supply chain effectiveness and performance?) 
4. Finally to analyze the effect of Organizational design and structure on the supply chain effectiveness and performance (How can the supply chain be affected by the design/structure of the organization?)

Organization design can be defined narrowly, as the process of changing organization structure and roles, or it can more effectively be described as the alignment of structure, process, rewards, metrics and talent with the strategy of the business (Drucker, 1973). Organization design may include strategic decisions, but is properly stated as a path to effective strategy execution. The design process nearly entails making trade-offs of one set of structural benefits against the others. Many companies fall into the trap of making repeated changes in organization structure, with little advantage to the business. This normally happens because changes in structure are relatively straightforward to implement while creating the impression which something substantial is occurring. This often leads to cynicism and confusion within the firm. More powerful change occurs when there are crystal clear design objectives driven by a new business strategy or forces in the market that require a different approach to organizing resources (Galbraith, 1995).

The organization design process is often defined in phases. Phase one is the definition of a business case, including a clear picture of strategy and design objectives. This step is typically followed by "strategic grouping" decisions, which will define the fundamental architecture of the organization essentially deciding which major roles will report at the top of the organization. The classic options for strategic grouping are to organize by:

- Behavior

- Function

- Product or category

- Customer or market

- Geography

- Matrix

Each of the basic building block options for strategic grouping brings a set of benefits and drawbacks. Such generic pros and cons, however, are not the basis for choosing the best strategic grouping. An analysis must be done completed relative to a specific business strategy (Nadler, 1992).

Organizing, the process of structuring human and physical resource in order to accomplish organizational objectives, involves dividing tasks into jobs, specifying the appropriate department for each job, determining the optimum number of jobs in each department, and delegating authority within and among departments. One of the most critical challenges facing lodging managers today is the development of a responsive organizational structure that is committed to quality. According to James Schermerhorn (2001), Jr., Professor, Ohio University "Organizational structure is perhaps the least understood and most under-appreciated topic in business." Organizational Structure is a topic seldom contemplated by most people working in organizational settings.

We all go to work every day, go to assigned locations, and perform our jobs — and we do not ever think about how our organization is arranged. However, Organizational Structure is critical both for a company and its employees. People should think very carefully about the organizational structure of the companies for which they work or of companies for which they intend to work. In the long run, Organizational Structure can spell the difference between success and failure for a company, as well as for the individuals who work there. 


\section{Factors to Consider}

\subsection{The four essential management functions}

The first thing to consider is that most people who study Management know that Organizational Structure is a crucial component of the overall business strategy, just as important as Planning, Leading, and controlling an organization.

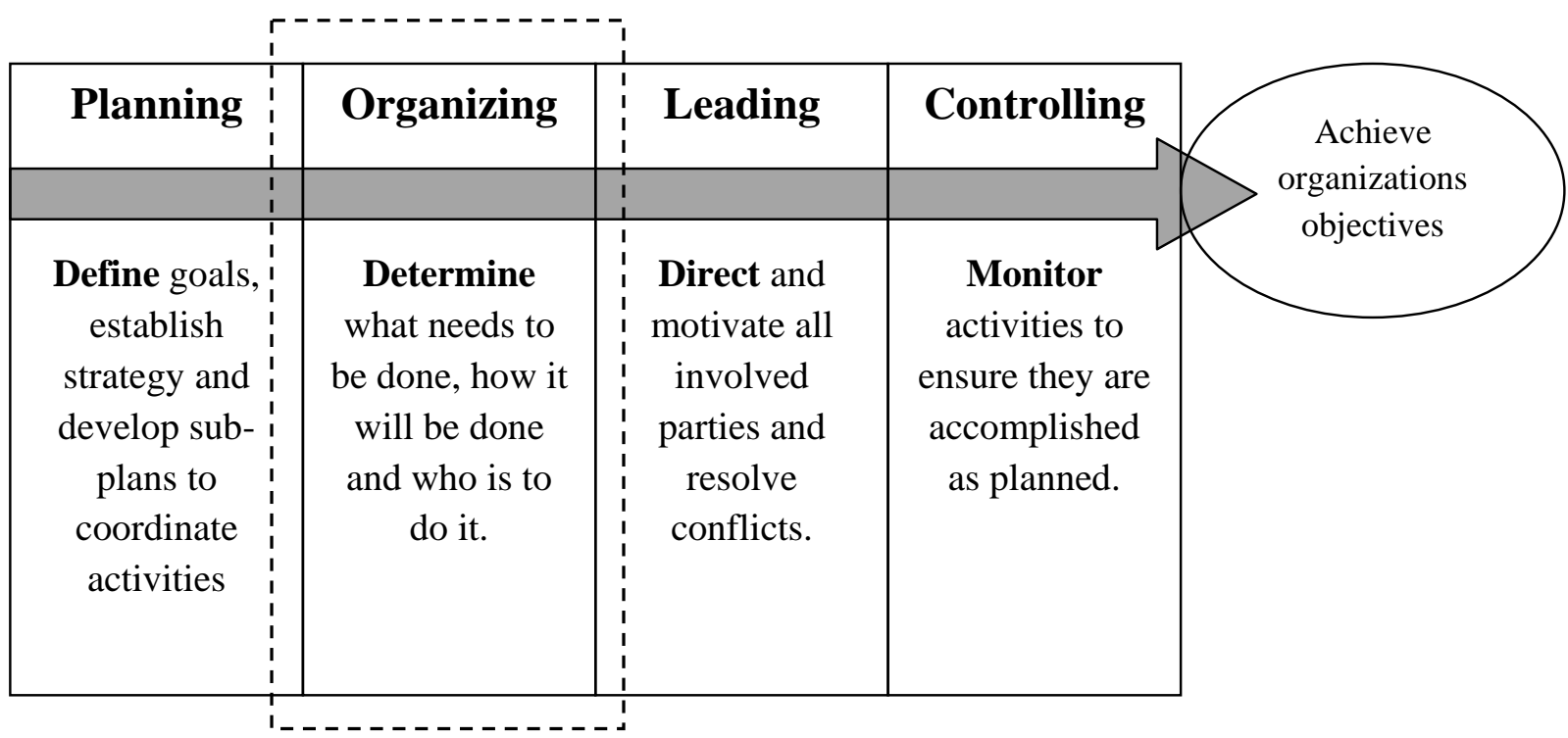

Fig. 1. Major Components for Achieving Organizational Objectives (Bateman, 2004)

In essence, Organizing is the manner in which a company utilizes its resources - specifically, its human resources. How do we organize jobs into departments? How do we answer the questions "who does what" and "who reports to whom" in the chain of command? There is also an implicit issue of how to coordinate all of these people and all of these duties across an extended enterprise. Organizational Structure is the framework for answering these questions and more.

\subsection{Flexibility of the Organization}

While many companies today are still reluctant to change their Organizational Structure, more and more are coming to find that they need to be adaptive and they need to be flexible. In fact, Management Theorists - people who study this at the academic level — are starting to encourage organizations to change their structure because they need to be prepared to respond to what we call "trigger points." A trigger point is an external event that has an impact on an organization. It could be a change in the markets; it could be a change in global competition; it could be the advent of new technology. These trigger points and any number of others calls for immediate responses, as well as organizational flexibility and adaptation (Mische 2001).

\subsection{Drivers of Change}

There are several reasons why organizations change their business strategies and Organizational Structures. The table below cites a number of these "drivers of change" and the key points of their impact on business, as well as examples of companies that adapted to such changes. 
Table 1

Drivers of Change and Their Impact on Business

\begin{tabular}{|c|c|c|}
\hline Employee Involvement & Participation in decision making & $\begin{array}{l}\text { - General Motors } \\
\text { - Hampton Inn Hotels } \\
\text { - SAS Airlines }\end{array}$ \\
\hline TQM & Continuous process improvement & $\begin{array}{l}\text { - Globe Metallurgical, Inc. } \\
\text { - Motorola } \\
\text { - Westinghouse }\end{array}$ \\
\hline Process Reengineering & $\begin{array}{l}\text { Redesigning work flow to drive out } \\
\text { waste }\end{array}$ & $\begin{array}{l}\text { - Hewlett-Packard } \\
\text { - Lotus Development } \\
\text { - Southwest Airlines }\end{array}$ \\
\hline Concurrent Engineering & $\begin{array}{l}\text { Integration of design, manufacturing, } \\
\text { support }\end{array}$ & $\begin{array}{l}\text { - British Aerospace } \\
\text { - Carolla Development } \\
\text { - Comdial Corporation }\end{array}$ \\
\hline Six Sigma & $\begin{array}{l}\text { Statistical control of variance; process } \\
\text { improvement }\end{array}$ & $\begin{array}{l}\text { - AlliedSignal } \\
\text { - General Electric } \\
\text { - Motorola }\end{array}$ \\
\hline Globalization & $\begin{array}{l}\text { Geographic dispersal, national culture, } \\
\text { laws }\end{array}$ & Most large organizations to varying degrees \\
\hline Business Model Reinvention & $\begin{array}{l}\text { Refine customer acquisition and } \\
\text { retention }\end{array}$ & $\begin{array}{l}\text { - IBM } \\
\text { - Ikon Office Solutions } \\
\text { - Southwest Airlines } \\
\end{array}$ \\
\hline
\end{tabular}

\section{Achieving sustainable supply chain}

\subsection{Seven Steps for Sustainability}

Today there is a lot of interest in building sustainable organizations. Companies are trying to burnish their brands by building their environmental bona fides. For instance, oil companies such as British Petroleum and Chevron have run advertisements touting their conservation and alternative energy initiatives.

Companies and their management practices also have profound effects on human beings and the social environment. And the evidence suggests that, in many instances, these effects are even more pervasive and more harmful than the effects on the physical world. They create waste and pollution and are threatening the existence of life on earth. As the population of the world increases and resource availability decreases, companies are starting to realize that supply chains must be redesigned. The supply chains need to be closed-looped, environmentally friendly and conserve and use as little resources as possible.

The future of supply chain management is sustainability. Forward thinking companies are already taking steps to develop sustainability within their supply chains. What is the secret to implementing sustainability? How can we create a sustainable supply chain? What changes must we make to our supply chains in order to become "sustainable" in today's business world? What processes or steps must we implement in order to achieve this goal of sustainability? According to O'Reilly (2000) there are seven steps that companies can take in order to become sustainable.

1) The first step is culture. Many companies are transfixed on short term results. The first industrial revolution was defective and has transformed us into a disposable society. Unfortunately we have trained our leaders on how to conduct business from a throwaway viewpoint. The assumptions these executives have had is "if it is within the law, we are allowed to do it regardless of the repercussions to the environment.” This is the first significant paradigm that must be changed. 
2) The second step to instituting sustainability within a corporation is to educate the organization on sustainability. It is imperative to show employees the benefits of sustainability and what it can do for a company and our environment.

3) The third step on our journey to sustainability is to complete a sustainability audit of our company's supply chain. We need to develop a baseline measure for where we are today in order to gauge where we need to go.

4) The audit results should help the organization with our fourth step, which is determining the goals and objectives for the sustainable supply chain. When developing goals and objectives, companies must make sure their goals are SMART (Specific, Measurable, Attainable, Relevant, and Timely) and that they are focused on sustainability.

5) Once we develop the sustainable goals for the organization, the fifth step would be to determine what actions need to take place in order to meet these objectives. A plan must be developed and projects assigned to help meet the sustainable goals of the company. The objective is to achieve a sustainable supply chain but unfortunately it will not happen overnight. This is a long arduous process and one that will take years to change. The actions and projects should facilitate this change and help us reach our goals and objectives.

6) Once the projects are in place the next step is to measure the sustainability progress. Measures must be in taken in order to see how effective we are with our projects. These sustainability measures must be posted and discussed at company meetings. Measuring objectives will drive results! Once we reach a measure we need to raise the bar and focus on getting more sustainability within our supply chain processes. If we are falling short of our measures we need to find out what is preventing us from reaching our goals?

7) Part of the last step on the journey to sustainability is benchmarking where your company is in regards to sustainability. Even though we have goals, and have projects and measures in place, we need to seek out other companies that are trying to achieve sustainability. The key to becoming sustainable is to develop a culture of sustainability within your organization. A company will reach sustainability when they produce no waste, exclusively use renewable resources, employ no hazardous materials in their process and develop products that are recycled or used in another form that benefits the environment and society. The Industrial Revolution is evolving into the Sustainable Revolution

\subsection{Organizational design and its sustainability- an effective synchronization}

Usually, organizational efforts to monitor and rehabilitate housing stock, improve water quality, protect lands, build an environmental education program, protect neighborhood resources or create economic viability for a community, etc., take much longer than two or three years. To have true impact and then to maintain what has been won or created, these efforts require groups can sustain their work over many years.

What does it take for community groups to create organizations that can truly sustain themselves and their critical work for the long haul? How can current volunteer and staff leaders modify and structure their work so that future leaders will have a dynamic and stable organization? What types of processes enable groups to adapt and change with the needs and context of their community's issues?

The following criteria outline key elements for organizational leaders to consider as they grapple with these questions and seek to create sustainable organizations. 
1. Vision, Mission, and Plan

2. Effective, Efficient and Focused Programs

3. Diverse fund raising effort

4. Accurate Financial Management and Budgeting

5. An Effective Governing Body or Board of Directors

6. Intentional Volunteer Leadership and Staff Development

7. Community Networking and Visibility

8. Appropriate Technology That Supports the Organization's Work

9. Clear Communication within a "Learning Environment"

10. Ability to Celebrate Successes and Enjoy the Work

\section{Factors influencing the supply chain effectiveness}

Managers in many industries, especially those in manufacturing, are trying to better manage supply chains. Important techniques/methodologies like just-in-time (JIT), total quality management, lean production, computer generated enterprise resource planning schedule (ERP) and Kaizen have been embraced. The concept of supply chain management (SCM), according to Thomas and Griffin (1996) represents the most advanced state in the evolutionary development of purchasing, procurement and other supply chain activities. At the operational level, this brings together functions that are as old as commerce itself - seeking goods, buying them, storing them and distributing them. At the strategic level, SCM is a relatively new and rapidly expanding discipline that is transforming the way that manufacturing and non-manufacturing operations meet the needs of their customers.

Development of cross-functional teams aligns organizations with process oriented structure, which is much needed to realize a smooth flow of resources in a supply chain. As suggested by Trent and Monczka (1994), such teams promote improved supply chain effectiveness. They minimize or eliminate functional and departmental boundaries and overcome the drawbacks of specialization, which according to Fawcett (1995), can distribute the knowledge of all value adding activities such that no one, including upper level managers, has complete control over the process. Such teams helped in the formation of modern supply chains by promoting greater integration of organizations with their suppliers and customers.

Thompkins (2004), in his famous book, says that, there are 15 major elements or factors that are the roadmap to an effective, flexible and proactively responsive distribution operation (Fig. 2.).

\section{Organizational structure and supply chain- An Integration Approach}

There are essentially three strategy types: Defenders, Analyzers, and Prospectors. Each type has its own unique strategy for relating to its chosen market and each has a particular configuration of technology, structure and process that is consistent with its market strategy (Miles 1978). Defenders primarily stay in their existing domains and stable market niches. Product development for these companies is limited to the improvement of existing products. Efficiency and control are important factors for these companies. Defenders tend to ignore developments outside of domain. Defender type organizations favor mass production. It involves a detailed functional division of labor and limited authority to lower level management i.e. most of the objectives are decided by top level management without considering the lower level management. Also, the customers have limited options, so delivery performance level suffers for defender type organizations. 
Prospectors are the most innovative type and emphasize the development of new products and technologies and the exploration of new markets. They try to be first in the market with new products, and continuously experiment with responses to emerging trends and changes in the market place. They are characterized by a low degree of formalization, and have greater decentralized decision making and higher flexibility. In prospector type organization higher authority is given to lower level management and they are involved in decision making along with top level management. Also the customers have variety of options and hence, delivery performance is of greater importance for the prospector type organization.

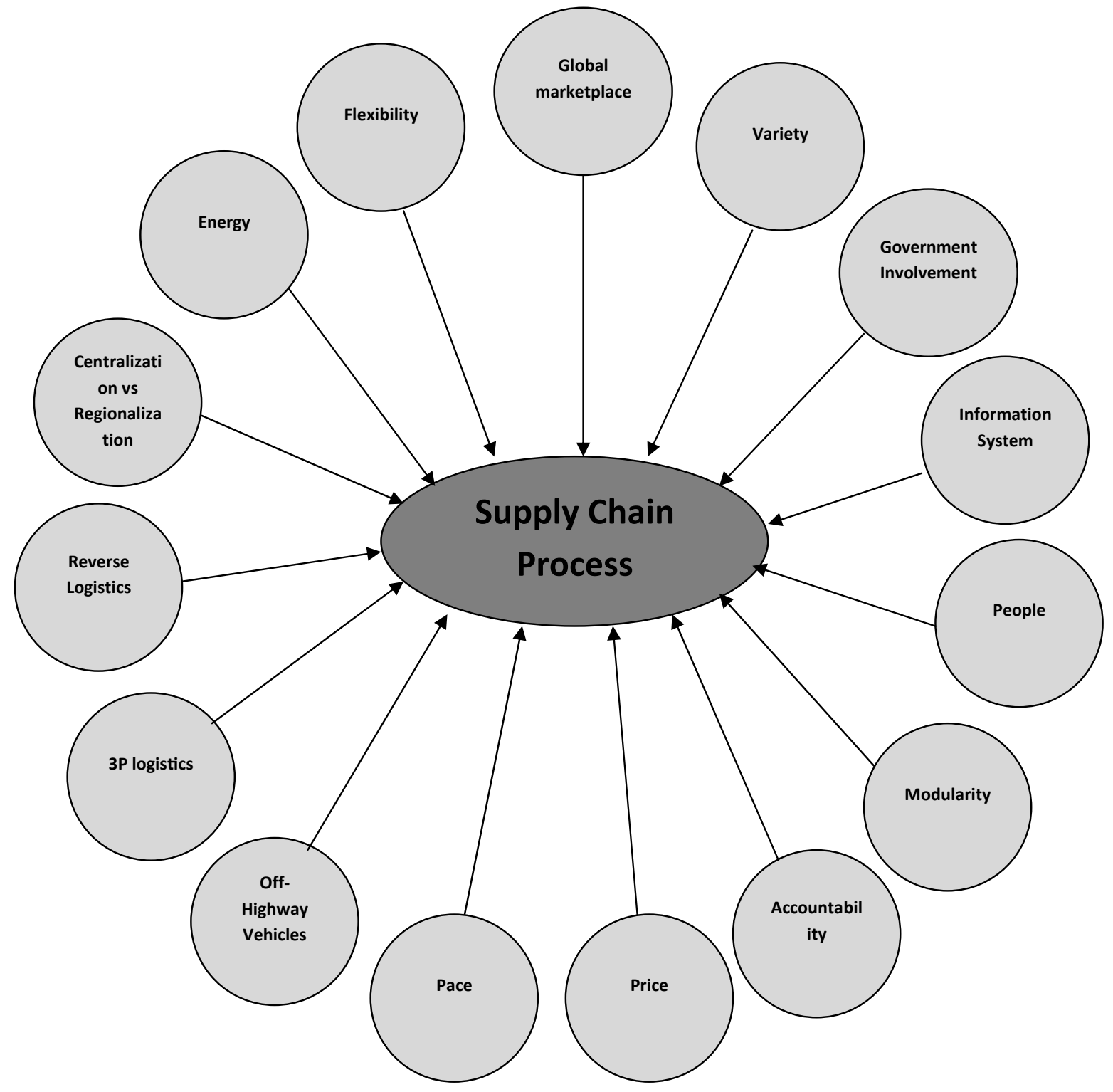

Fig. 2. Factors affecting supply chain

Analyzers try to combine the exploration capability and innovativeness of the prospectors with the defenders ability to serve existing markets effectively. These companies pursue efficiency in the stable markets they serve, and try to be adaptive to and prepared for change in the turbulent markets in which they are also active at the same time. However, analyzers are not first movers. Rather their focus is on quick adoption of new concepts launched by successful prospector companyies.

We have constructed a model showing the relationships between a typical organization and the supply chain which is represented in Model-A. 


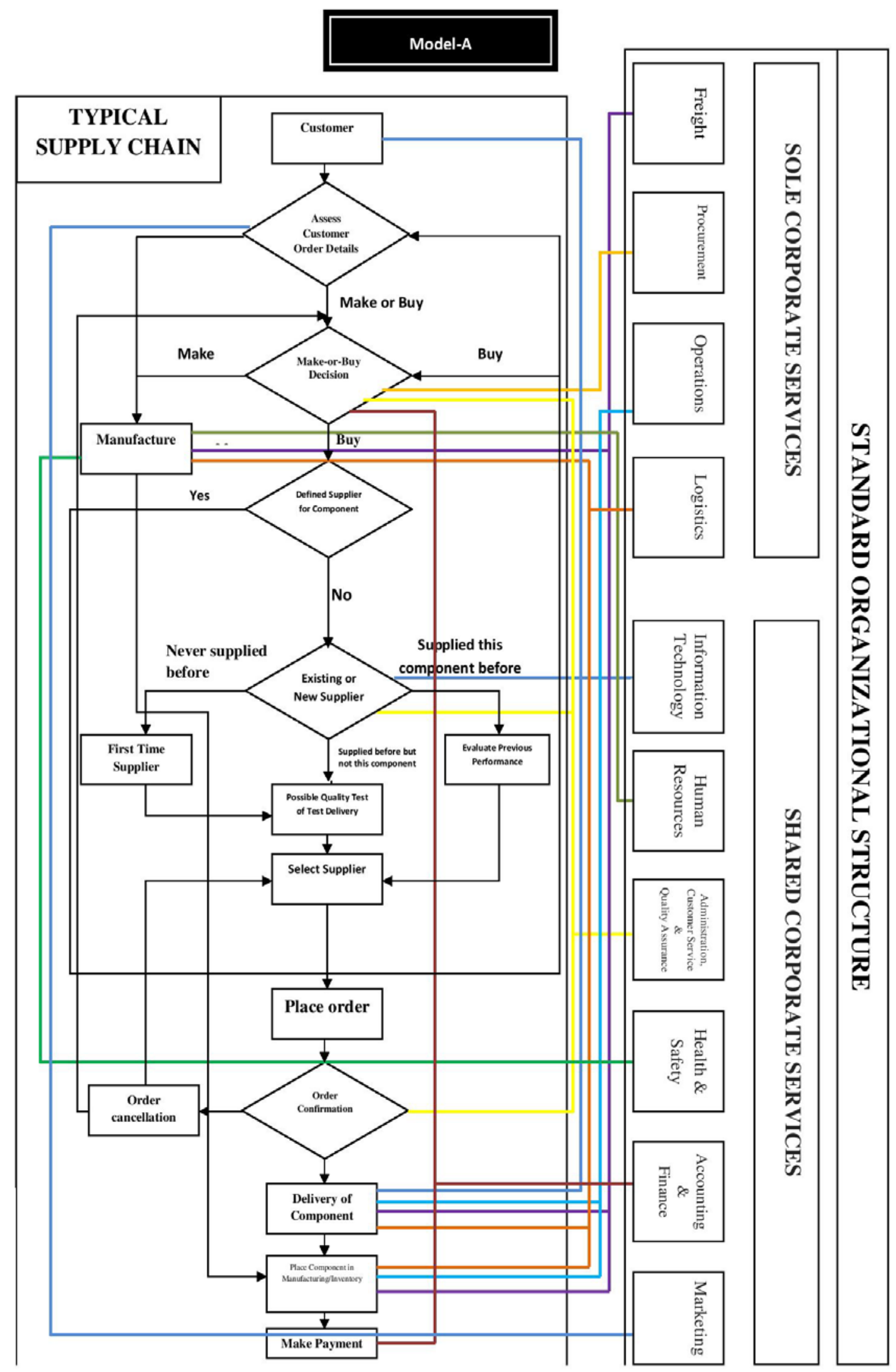




\section{New Propositions}

\subsection{Organizational structure}

It can be said that most appropriate basic SC structure for defender, prospector and analyzer type of organization is mechanistic, organic and matrix respectively. SC activities may have positive effect on the organization if there is no conflict between them. We can reduce these conflicts by assigning the responsibility to each of the SC activities as clear as possible.

SC structure for analyzer requires higher level of cost efficiency and delivery performance, medium level of formalization, centralization, innovation, flexibility and standardization. Such types of characteristics can be achieved by having a matrix type of SC structure (Thompson 1965) with each of the department having its relevant SC activities. For firms employing this type of organization, SC department focuses on coordination and connection with other departments for efficient utilization of SC activities rather than the direct control of SC activities (Kim 2007) According to Miles and Snow (1978), Analyzers main problem is how to differentiate the organization's structure and processes to accommodate both stable and dynamic areas of operations. As they try to be cost efficient as well as updated with the new product -market relationship, so marketing and production department plays a major role.

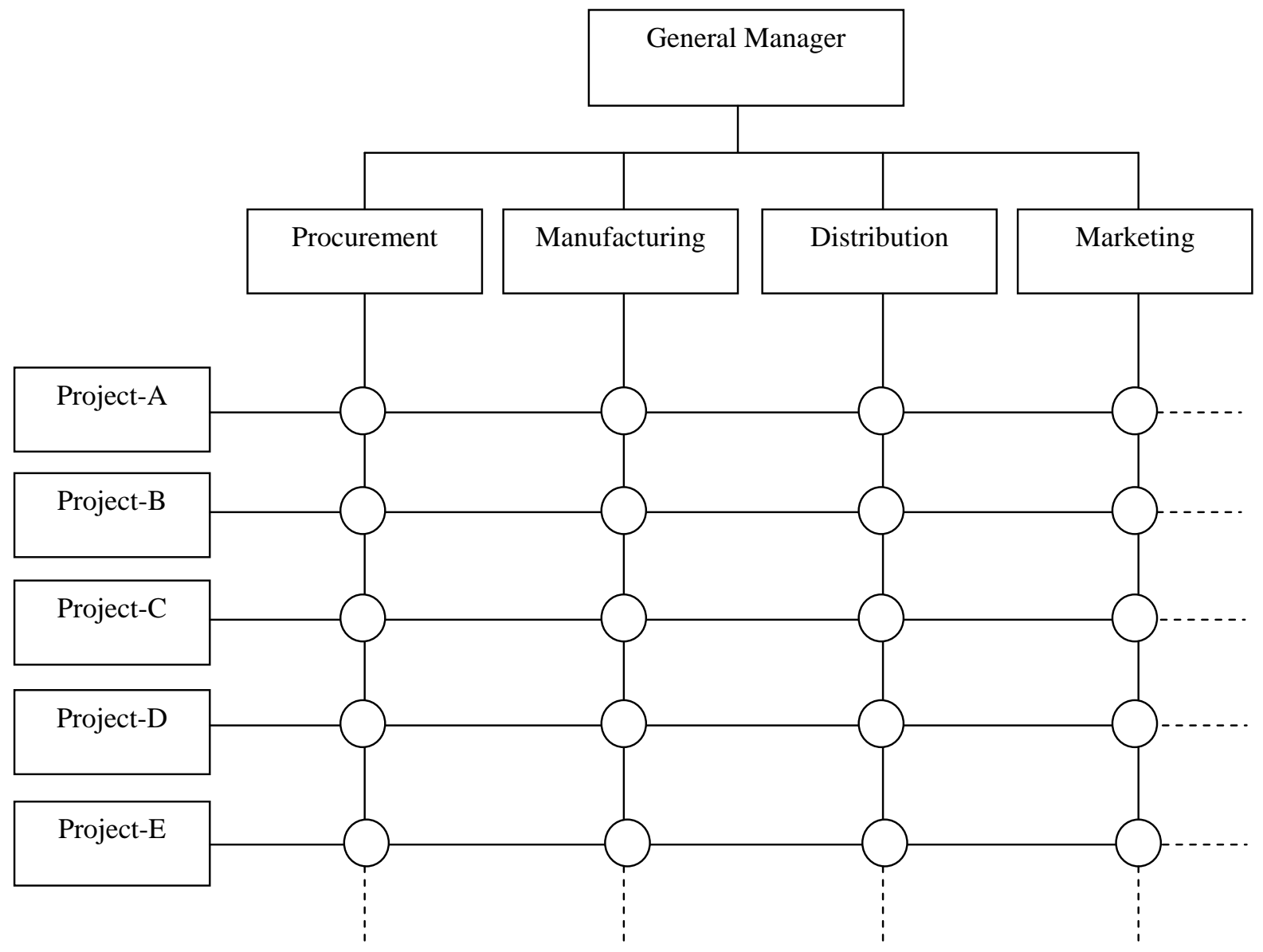

Fig. 3. Matrix structure of organization

\subsection{Supply Chain Strategy}

"Supply chain thinking" is a better characterization. This term infers a more gradual infusion of new mindsets and methods into traditional tasks. Most managers have the same concerns today as managers had ten or 50 years ago. These concerns include products, markets, people and skills, 
operations, and finance. Supply chain thinking brings change to the tasks managers perform in dealing with these issues.

Figure-4 shows the relationship of the tasks. Supply chain design begins with strategy, so it is at first. Porter's (1996) framework begins with strategic themes. Strategic themes are the cornerstones of a supply chain strategy. The themes require clear choices regarding how to compete. This is a difficult but necessary step and not to be taken lightly. Too often companies try to be all things to all people. Failure to choose how one will compete means there is no strategy at all.

The remaining tasks, including the development of information systems, need to align with these strategies. This article describes practical ways to bring supply chain thinking to the task of strategic planning. Too often strategic planning goes on in an operational vacuum. Gaining advantage from supply chains requires cross-functional thinking that is uncommon in most companies.

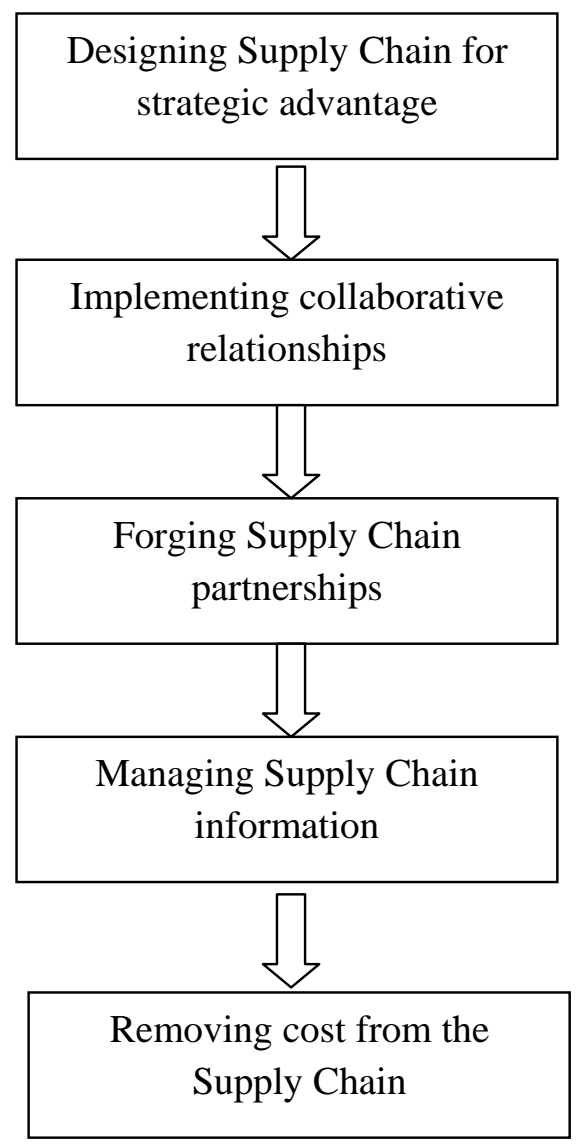

Fig.4. Tasks of supply chain strategy

\section{Established Hypotheses}

We suggest the following hypothesis on the basis of above arguments.

Hypothesis-1: 'Analyzer' organizations stress higher efficiency and effectiveness and this could be achieved by choosing a matrix type of structure for the basic infrastructure. 
Hypothesis-2: For an effective and efficient supply chain strategy implementation each supply chain task or mission should be assigned as a project to a project manager who will work in collaboration with the functional or divisional managers and combine people from various divisions or functional departments into the project or business team.

Hypothesis-3: To ensure teamwork and establish group leadership instead of individual leadership, organic organization principles should be adopted for the information flow that is people in it should be equally leveled, with no job descriptions or classifications, and communication to have a hubnetwork-like form. Each supervisor or manager would work like an hub for information exchange.

\section{Proposed Organizational Model based on the Hypothesis}

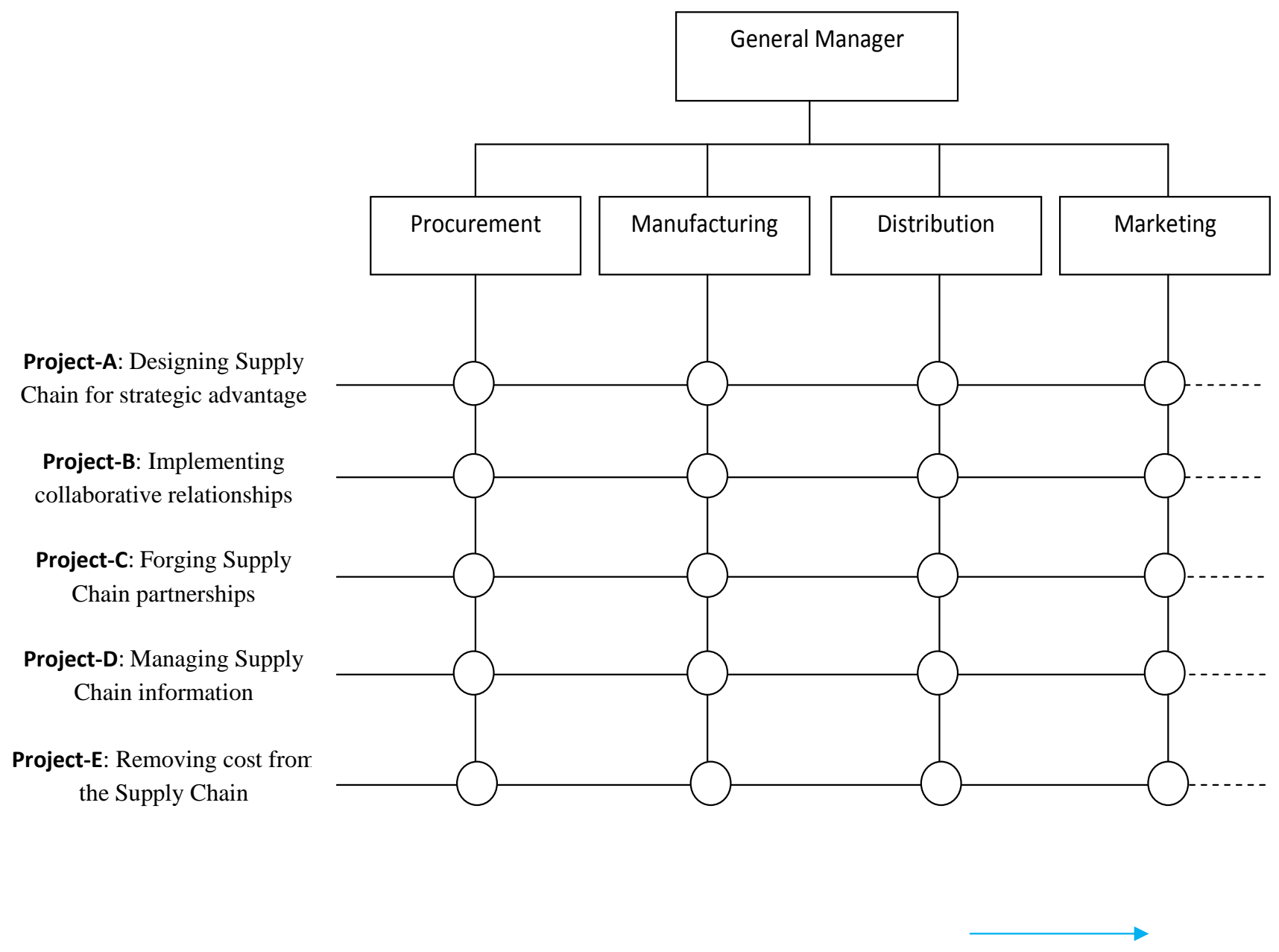

Model-B: Proposed Organizational Model

Through this research, we have tried to find a correlation between the organizational structure and the sustainable supply chain. By following the steps, described above, one organization can metamorphose to an effective sustainable supply chain. The relation between the organizational structure and the implementation is widely described in this paper. Upon adopting this organized structure, an organization can monitor its metamorphosis and also will be able to continue its journey towards the sustainable supply chain. The adoption of this type of organization structure will definitely increase the efficiency of the effective decisions. With a clearly defined responsibility, 
employers will be more motivated to work and achieve the ultimate goal of the organization. Thus our newly proposed organization structure can work as a motivating tool as well.

\section{Conclusions}

Organizational structure and the sustainable chain has always been a major research area, separately. But in different management papers and journals, a clearly defined relationship between the organizational structure and the sustainable supply chain was absent. Through this paper, we have tried to relate the organizational structure with the supply chain process and the impact on the effectiveness of the whole supply chain was analyzed. The new propositions about the organizational structure will definitely help the organizations to monitor and implement the sustainable supply chain. This model may vary to some extent for different types of organizations. For example, there will remain some differences between the structures of a RMG industry and a FMCG industry. But this proposed model will act as a beaconing tool to provide a general idea to contribute to knowledge through a systematic evaluation and synthesis of current knowledge and practice in relation to organizational design in the context of emerging supply chain management perspectives.

\section{References}

Bateman, T.S. \& Snell, S. (2004). Management: The New Competitive Landscape, 6th ed., McGrawHill, p. 13

Champoux, J.E. (2000). Organization Behavior - Essential Tenets for a New Millennium. SouthWestern College Publishing, Cincinnati, OH, p. 325.

Drucker, P. F. (1973). Management: Tasks, Responsibilities, Practices. New York: Harper \& Row, 52.

Fawcett, S.E. (1995). Using strategic assessment to increase the value-added capabilities of manufacturing and logistics. Production and Inventory Management Journal, 36(2), 33-37.

Galbraith, J. R. (1995). Designing Organizations: An Executive Briefing on Strategy, Structure and Process. San Francisco: Jossey-Bass, 67.

Hamel, G., \& Pralahad, C.K. (1994). Competing for the Future, Harvard Business School Press, Cambridge, MA, as referenced in D. Hellriegel, J.W. Slocum and R.W. Woodman, Organizational Behavior, South-Western College Publishing, Cincinnati, OH, 2001, p. 474.

Hart, S. L. \& Ahuja, G. (1996). Does it pay to be green? An empirical examination of the relationship between emission reduction and firm performance. Business Strategy and the Environment, 5(1), 30-37.

Jayaram, J., \& Tan, C. (2010), Supply chain integration with third-party logistics providers. International Journal of Production Economics, 125, 262-271.

Kim, S.W. (2007). Organizational structures and the performance of supply chain management. International Journal of Production Economics, 323-345.

Miles, R.E., Snow, C.C., Meyer, A.D., \& Coleman, H.J. (1978). Organizational strategy, structure and process. Academy of Management Review, 546-562.

Mische, M.A. (2001). Strategic Renewal: Becoming a High-Performance Organization. Prentice Hall, 23.

Mukhopadhyay, S. K., \& Setaputra, R. (2006). The role of 4PL as the reverse logistics integrator: Optimal pricing and return policies. International Journal of Physical Distribution \& Logistics Management, 36 (9), 716-729.

O’Reilly, C. A., \& Pfeffer, J. (2000). Hidden Value: How Great Companies Achieve Extraordinary Results with Ordinary People. Boston: Harvard Business School Press.

Porter, M. E. (1992). What is Strategy. Harvard Business Review, November December, 1996. 
1154

Nadler, D.A., Gerstein, M.S., \& Shaw, R.B. (1992). Organizational Architecture: Designs for Changing Organizations. San Francisco: Jossey-Bass, 78.

Romano, P. (2003). Coordination and integration mechanisms to manage logistic processes across supply networks. Journal of Purchasing and Supply Management, 9, 119-134.

Schermerhorn, J., \& Leenders, M.R. (2001) The supply organizational structure dilemma. The Journal of Supply Chain Management, 37(3), 4-11.

Silvestri, G.T. (1997). Occupational Employment Projections to 2006. Monthly Labor Review, (120), 39-57.

Tompkins, A. J., \& Harmeling, D. (2004). The Supply Chain Handbook. Tompkin Press, 24-35.

Thomas, D.J., \& Griffin, P.M. (1996). Co-ordinated supply chain management. European Journal of Operational Research, 94 (3), 1-15.

Thompson, A. (1965). Organization in Action. International Journal of Physical Distribution \& Logistics Management, 36 (9), 564-565.

Trent, R.J. (2004). The use of Organizational Design features in purchasing and supply management. The Journal of Supply Chain Management, 40(3), 4-18.

Trent, R.J., \& Monczka, R.M. (1994). Effective cross-functional sourcing teams: Critical success factors. International Journal of Purchasing and Materials Management, 30 (4), 3-11. 